\title{
Dermatological problems of the puberty
}

\author{
Beata Bergler-Czop, Ligia Brzezińska-Wcisło \\ Department of Dermatology, Silesian Medical University, Katowice, Poland \\ Head: Prof. Ligia Brzezińska-Wcisło MD, PhD
}

Postep Derm Alergol 2013; XXX, 3: 178-187

DOI: 10.5114/pdia.2013.35621

\begin{abstract}
Puberty is a period of life between childhood and adulthood. It is characterized by many changes in morphology and appearance of the body (biological maturation), in the psyche - development of personality (psychological maturation), and in the attitude towards one's own and the opposite sex (psychosexual maturation), and in the social role (social maturation). Dermatological problems of adolescence are mainly related to fluctuations in hormone levels, mainly androgens. They include acne, hair problems and excessive sweating. Acne vulgaris is the most frequently diagnosed dermatosis in patients aged between 11 and 30 years. It is believed that it affects about $80 \%$ of persons in this age group or even, taking into account lesions of low intensity, $100 \%$ of young people. Excessive sweating is a condition characterised by excessive production of sweat, resulting from high activity of sweat glands. The sweat glands are localised in almost all areas of the body surface but on the hands, feet, armpits and around the groin they are found at the highest density. Seborrhoeic dermatitis of the scalp is a chronic, relapsing, inflammatory dermatosis, which currently affects about $5 \%$ of the population. It affects mostly young people, particularly men.
\end{abstract}

Key words: puberty, acne, hyperhidrosis, hair.

\section{Introduction}

Puberty is a period of life between childhood and adulthood. It is characterized by many changes in morphology and appearance of the body (biological maturation), in the psyche - development of personality (psychological maturation), and in the attitude towards one's own and the opposite sex (psychosexual maturation), and in the social role (social maturation). The process itself depends on genetic, gender, environmental, climatic and cultural factors [1, 2]. The preparing phase, pre-puberty, lasts about 2 years and it starts between 6 and 8 years of age, gradually intensifying. The puberty lasts about 4 years, between 10 and 16 years of age. The post-puberty phase takes place between 18 and 25 years of age $[3,4]$.

Dermatological problems of adolescence are mainly related to fluctuations in hormone levels, mainly androgens. They include acne, hair problems and excessive sweating.

\section{Acne vulgaris}

Acne vulgaris is the most frequently diagnosed dermatosis in patients aged between 11 and 30 years. It is be- lieved that it affects about $80 \%$ of persons in this age group or even, taking into account lesions of low intensity, 100\% of young people. Lesions which usually appear in the second decade of life, are less and less intense as the time goes by and subside at the end of this decade or at the beginning of the third one. However, there are cases of persistence of the disease process until $30^{\text {th }}$ or even after $40^{\text {th }}$ year of age $[5,6]$.

In $95 \%$, lesions are situated on the face and on the upper parts of the trunk, occasionally on other parts of the body and due to this location and the chronic nature of the disease, it many times poses a serious psychological problem for a patient.

\section{Views on the etiopathogenesis of acne vulgaris}

Acne vulgaris is a chronic inflammatory disease affecting seborrheic areas (mainly: chest, face, back), characterized by, inter alia, the presence of comedones, papular eruptions, pustular eruptions, purulent cysts and scars.

The etiopathogenesis of acne is multifactorial. In all patients with acne, the following symptoms occur: excessive sebum production, excessive keratosis of excretory

Address for correspondence: Beata Bergler-Czop MD, PhD, 42-624 Ossy, 2a Leśna St, Poland, phone/fax: +48 322840877 , e-mail: bettina2@tlen.pl

Received: 4.09.2012, accepted: 10.02.2013. 
ducts and openings of sebaceous glands, development of bacterial flora and release of inflammatory mediators in the skin [4-9].

The microcomedone is a primary change which starts the whole inflammatory cascade. Different factors may induce formation of microcomedones, such as: linolenic acid deficiency, excessive secretion of androgens or excess of free lipid acids. Intrafollicular keratinisation of a microcomedone leads to its development into a comedone [4]. It is accompanied by excessive production of tonofilaments, desmosomes and keratins K6 and K16, and together with transglutaminase, it results in development of a keratinised "envelope". Altogether, this process leads to closure of a follicle opening and it impedes removal of the sebaceous gland contents onto the skin surface. Proinflammatory cytokines, mainly IL-1, are also involved in the keratinisation process [5-7].

In the process of formation of the comedo, the lipid contents of the hair follicle also play a role (Figure 1) [4]. Sebum within glands and excretory ducts is sterile and does not contain free fatty acids. Bacterial colonization (in particular, of Propionibacterium acnes (P. acnes), owing to appropriate enzymes, enables hydrolysis of sebum components to free fatty acids having the irritating and chemotactic effect [9-12]. Currently, it is believed that this is not the only component playing a role in the aetiology of acne. Gollnick et al. [13] attribute a huge importance to squalene oxidization and deficiency of linoleic acid. One put forward a hypothesis that intensified sebum secretion favours deficiency of linoleic acid which intensifies comedogenesis [14].

Excessive production and accumulation of sebum and closing of the follicle outings promote development of microorganisms. Microcomedones are colonised mainly by an anaerobic bacterium - P. acnes $[13,15,16]$.

Excessive sebum production and accumulation and blocked sebaceous gland openings favour bacterial colonization. Microcomedones are inhabited mostly by P. acnes. Other bacteria are, inter alia: Staphylococcus epidermidis and Pityrosporum ovale [14]. Due to the presence of lipase, this microorganism hydrolyses sebum di- and triglycerides to free fatty acids. Free fatty acids which arise during the hydrolysis process, have the irritating, pro-inflammatory effect and intensify follicular keratosis. Also hyaluronidase, proteases and neuraminidases, produced by $P$. acnes, have the proinflammatory effect. Moreover, this microorganism releases low-molecular chemotactic factors (peptides), attracting neutrocytes and it activates both the alternative complement pathway and a classic immune response. The activator of the alternative complement pathway is the cell wall of $P$.acnes which contains mannose [17-19].

Under the influence of $P$. acnes, peroxide anions are massively produced by keratinocytes which in combination with nitric oxide form peroxynitrates contributing to disintegration of keratinocytes [20-22].
Vega et al. [21] and Elsaie et al. [22] inform of the importance of Toll-like receptors (TLR receptors) which are a part of the innate cellular immune response. Receptors of this group are located, inter alia, on keratinocytes and in epidermal Langerhans cells. TLR2 (Toll-like receptor-2) present in monocytes identifies the elements of walls of Grampositive bacteria, inter alia, P. acnes [24].

Although no primary immune disorders were found in patients with acne, however, an overreaction of the immune system to $P$. acnes antigens is observed, which is expressed by the increased antibody titre as well as excessively intensified inflammatory response to intracutaneous injection of $P$. acnes, when compared to the healthy population. In some patients, excessive production of IgA and hypersensitivity to standard allergens used in tests have been observed [23, 25].

It was also demonstrated that immune disorders, apart from the inflammatory response, precede hyperproliferation of keratinocytes in a way resembling the type IV allergic reaction. Cytokines activated this way stimulate endothelial cells to produce vascular inflammatory markers - E-selectin, vascular cell adhesion molecules (VCAM-1), and HLA antigens of leukocytes in blood vessels around the hair follicle [10].

The pro-inflammatory cytokines released in a cascade manner in acne activate the AP-1 transcription factor (activator protein). The AP-1 induces genes of intracellular matrix metalloproteinase (MMP) which cleaves and reconstructs the skin matrix.

The complement activation by the microcomedo components is additionally increased by antibodies against $P$. acnes. Thus, initiation of the humoral response exacerbates the inflammatory reaction in acne. Hence, it is suggested that patients with acne have genetically determined hypersensitivity to $P$. acnes [10].

Melnik [26] investigated the role of Fox01 in the pathogenesis of acne. The author examines the aetiology of acne at the genome level and regards the deficit of the Fox01 nuclear transcription factor as fundamental. The Fox01 factor is a suppressor of many receptors, inter alia, the androgen receptor. It takes part in biosynthesis of lipids and proinflammatory cytokines. The increase in growth factors in

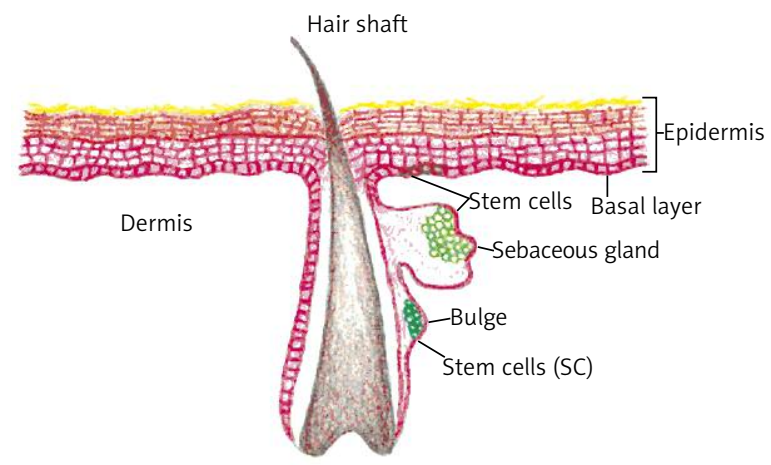

Fig. 1. Hair follicle with sebaceous gland (www.njms.umdj.edu) 
the puberty period and the so-called "western" lifestyle stimulate export of Fox01 beyond the cell nucleus to cytoplasm through the activation of the phosphoinositide 3-kinase pathway (PIK3). Using this mechanism, genes and nuclear receptors cause an increase in the level of receptors for androgens (blocking of suppression), increase in the level of androgen-dependent cells, intensification of lipogenesis and increased production of TLR2-dependent pro-inflammatory cytokines. Retinoids, antibiotics and proper diet may cause an increase in nuclear Fox01 and normalize the above-mentioned processes, which has an antiacne effect.

The activity of the pilosebaceous unit is regulated by sex hormones. Keratinocytes of hair follicles and sebocytes are a target for androgens, indirectly and directly. Androgens stimulate proliferation of keratinocytes, size of sebaceous glands and sebum secretion. Apart from endogenous androgens, acne lesions may also be induced by hormonelike lipids, androgens from diet and neuropeptides [26].

The puberty process is characterized by the increased release of gonadotropins by the anterior lobe of the pituitary gland which stimulates production of estrogens and androgens. Sebaceous gland cells have receptors for androgens on their surface. In women, the source of these hormones are: adrenal cortex and ovaries, while in men - adrenal cortex and testicles. In acne etiopathogenesis, first of all, the testosterone derivative $-5 \alpha$-dihydrotestosterone (DHT) plays a role, which originates from testosterone under the influence of the enzyme - $5 \alpha$-reductase. There are two types of $5 \alpha$-reductase: type I, present in the central nervous system, showing the activity in sebaceous glands and in the liver and type II, present in the liver and sexual organs (inter alia, in the prostate), acting within hair follicles of the hairy skin of the head, chin and chest [27]. In women, the main precursor of $5 \alpha$-dihydrotestosterone is androstenedione which may be transformed by means of $5 \alpha$-reductase into $5 \alpha$-androstenedione being the precursor of DHT or by means of $17 \beta$-hydroxysteroid dehydrogenase into testosterone which, in turn, produces DHT under the influence of $5 \alpha$-reductase [28].

The activity of testosterone and its derivative $-5 \alpha$-dihydrotestosterone is also affected by the concentration of transporting proteins in serum [29]. Kurokawa et al. [30] are of the opinion that high glycemic index food and milk increase the tissue level of $5 \alpha$-dihydrotestosterone, hence it may be possible that this group of foodstuffs has an influence on exacerbation of acne lesions.

Sebocytes are also able to produce androgens from cholesterol through P-450 cytochrome system enzymes [31].

In metabolism of lipids within sebocytes, peroxisome proliferator-activated receptors (PPAR) also play a role. Secretion of androgens additionally stimulates PPAR expression which affects differentiation of sebaceous gland cells [5].

Bellew et al. [32] confirmed a significantly higher concentration of androgens in serum of women with acne, when compared to healthy women. This phenomenon has not been observed in men. Also, an increased activity of $5 \alpha$-reductase and $17 \beta$-hydroxysteroid dehydrogenase in epidermis and hair follicles was observed in patients with acne when compared to the healthy population. On the other hand, Wolska et al. [33] think that there is no correlation between exacerbation of acne and other symptoms of hyperandrogenism in women. Yet, they assume the occurrence, in persons with acne, of an increased reaction of sebaceous glands to physiological concentrations of androgens.

Estrogens, in a natural way, through the feedback axis, inhibit production of androgens and thus of sebum. They also have a local effect, namely they reduce sebum secretion, affecting directly $\alpha$ and $\beta$ subunits of estrogen receptors which are located in sebaceous glands of hair follicles $[9,34]$.

The role of progesterone is not unequivocal. Natural progesterone in physiological conditions does not intensify seborrhoea, however, its synthetic equivalents have an effect stimulating sebum secretion [29, 35, 36].

So far, few studies have regarded the action of thyroid hormones at the level of sebaceous glands. More than 10 years ago, Ahsan et al. [37] proved the presence of nuclear receptors for thyroid hormones on sebocytes. Thyroidectomy reduces the rate of sebum secretion in rats and hormonal supplementation reverses this effect [11].

Also, the presence of MCR-1 and MCR-5 receptors for melanocortins ( $\alpha-M S H, A C T H$ ) has been found on sebaceous gland cells, which justifies the increase in sebum secretion and, thereby, exacerbation of acne in stress situations where the level of ACTH increases [38].

There are also other hormones which may cause intensified sebum secretion. They include inter alia growth hormone (growth factor-GH), insulin-like growth factor (IGF), insulin, thyroid-stimulating hormone (TSH), hydrocortisone, corticotropin-releasing hormone $(\mathrm{CRH})$ and $\mathrm{P}$ substance $[9,39]$.

The genetic basis of acne vulgaris has not been precisely confirmed. Probably, what is important here is multigene inheritance or autosomal dominant inheritance with different gene penetration [25, 40].

On the other hand, a statistically significant difference was observed in repetitions of the CAG region of the androgen receptor gene in healthy men and men with acne. The average number of repetitions of this region was 22.07 in men from the control group and 20.61 in men with acne. This difference did not refer to women. The results suggested a possibility to use polymorphism of repetitions of the CAG region of the androgen receptor gene as the acne marker in men [41].

In comparison to healthy persons, the hair follicles of patients with acne are characterized by a severe reactivity to the factors such as some cosmetics, corticosteroids, isoniazid, potassium iodide, expressed as a formation of microcomedones and comedones. The reason for this phenomenon is unknown $[9,42]$. 
Climate conditions are said to be one of factors influencing the condition of skin lesions in patients with acne, as in $60 \%$ of them an improvement was observed during summer and spring months. The exception is acne Mallorca where skin lesions appear in summer and spring. Acne vulgaris is more frequently present in urbanized areas, which may be related to environmental pollution [42].

Also, a higher frequency of disease cases in regions with tropical and subtropical climate is noticed, which is the socalled tropical acne [9].

Melnik [26] and Marcason [43] stressed a potential role of modern diet in the occurrence of acne lesions. Insulinotropic food, especially milk and carbohydrates with a high glycemic index as well as smoking, influence the changes in the level of the growth factor similarly as it happens in the puberty period. Growth factors activated by food stimulate phosphoinositide 3-kinase of oncogenes, activate signalling pathways, through the increase in the number of receptors for androgens and stimulate Fox01dependent genes stimulating proliferation of keratinocytes and lipogenesis of sebocytes.

\section{Sebaceous gland}

Sebaceous glands regulate independent endocrine functions of the skin, take part in hormonal ageing, and also have a direct and indirect antibacterial effect (through the activation of the TLR-2 receptor). This organ is characterized by expression of antibacterial peptides and pro-inflammatory cytokines. An interesting aspect of the sebaceous gland's function is production of corticotropin as well as protein binding this hormone and its receptors. This production, as a reaction to stress, is most probably responsible for exacerbation of acne in stress situations.

In neonates, sebaceous glands are big and remain under hormonal control from the period of intrauterine life (mother's androgens, passing through the placenta during pregnancy and breast-feeding) and of neonate's own androgens (synthesized by testicles and adrenal glands between 9 and 15 week of pregnancy). In this period of life, susceptibility to development of acne is very high, which, many times, in combination with improper skin care leads to development of serious forms of acne in neonates and infants [5, 44].

In the prepubescent period, sebum secretion is reduced, however, in children aged 7 secretion increases, which is related to the activation of adrenal cortex. During puberty, sebum synthesis reaches its maximum value and then it slowly decreases along with reduction in production of androgens [45].

It was proved that in the prepubescent period (in children between 5.5 and 12 years of age), sebum secretion increases with age, while the period of colonization of $P$. acnes is visible just in the puberty period [4].

In all parts of the body, sebaceous glands have a similar structure. The majority of them are bound with hair fol- licles (except for ectopic glands of lips and other mucous membranes). Acne occurs mainly in the areas of so-called sebaceous follicles, i.e. a large sebaceous gland is associated with a medium-sized hair. The increase in the level of androgens during the puberty period does not affect their structure as the structure of the sebaceous gland in a child and in an adult is the same [4]. Androgens only make glands bigger, which leads to increased sebum secretion.

Sebum plays an important role in the aetiology of acne. It has been proved that limiting sebum secretion favours the clinical improvement in patients. Currently, however, it is known that excessive sebum secretion is a not a condition of the occurrence of acne, as in many diseases, e.g. Parkinson's disease, sebum secretion is very high and no acne occurs [4].

A primary eruption in acne is a microcomedo. By definition, it is a follicle within which there is a hindrance preventing sebum drainage (follicle proliferation and so-called retention hyperkeratosis) [6]. Microcomedones may be subject to spontaneous regression or evolve into non-inflammatory or directly inflammatory acne eruptions [4, 9].

The presence of the microcomedo may be detected by a microscope test only (the picture shows proliferation of corneocytes blocking the bulbously distended opening of the hair follicle) $[46,47]$.

Eruptions in the course of acne are usually located within the areas where sebaceous glands are abundant, particularly in the face area (nose, forehead, chin, cheeks), the back area (neck and interscapular region) and in the upper part of the chest. In addition to the typical areas, areas such as armpits, groin, and buttocks can also be involved (acne inversa) [4, 48, 49].

A characteristic feature of acne is the polymorphism of its clinical morphology. Eruptions can be divided into three groups: primary non-inflammatory changes, secondary inflammatory changes, post-inflammatory changes and scarring.

Primary non-inflammatory changes include microcomedones; closed comedones called whiteheads, observed in the stretched skin as lumps with a visible opening of the hair follicle, upon pressure, whiteheads come out with a whitish, gritty content; open comedones (socalled blackheads) develop from closed comedones or directly from microcomedones, are filled with keratin, sebum and bacteria, show a dark coloration of the distal part due to the oxidation of keratin and sebum, also accumulation of melanin.

Secondary inflammatory changes in the course of acne are papules and pustules developing after destruction of the hair follicle epithelium, accompanied by infiltration of neutrophils and lymphocytes (develop from blackheads or directly from microcomedones); nodules, resulting from chronic inflammation, clinically resembling cysts but they lack histological features of cysts; abscesses most frequently forming from grouped papules, pustules and nodules; fistulas, characteristic of severe acne, located usually in the 
naso-labial areas, around the jaw and neck and reaching up to $10 \mathrm{~cm}$ of length.

Post-inflammatory changes can be characterised by fistulas between comedones, linked by the scar tissue, developing from abscesses and scarring comedones; epidermal cysts (localised mainly in the retroauricular area and eyebrows) and hypertrophic scars [46].

\section{Most important kinds of acne}

According to Braun-Falco et al. [4], the following types of acne can be identified: vulgaris, inversa, fulminans, steroid, mechanic, contact, androgenic, pre-menstrual, postmenstrual, post-menopausal, infant and child, from selfdestruction, inflammatory acne with facial oedema and acne-like changes (Figures 2-4).

\section{Treatment of acne}

The rules of therapy are best described by the consensus of 2009 (Table 1) [10].

\section{Hyperhidrosis}

Excessive sweating (Latin hyperhidrosis) is a condition characterised by excessive production of sweat, resulting from high activity of sweat glands. The sweat glands are localised in almost all areas of the body surface but on the hands, feet, armpits and around the groin they are found at the highest density. Furthermore, sweat glands can be divided into eccrine, apocrine and apoeccrine [4, 50]. The eccrine sweat is odourless, and its secretion is stimulated primarily by heat and emotional stress. After birth, the apocrine glands occur in the areas of the genital organs, anus, navel and nipples. Their size and activity increase during puberty. The secretions of apocrine glands on the surface of the skin are degraded by bacteria resulting in an unpleasant body odour. The role of apocrine glands in humans is unclear. Probably they play a role of sexual attractants.

The eccrine glands are mostly responsible for excessive sweat production. The following types of hyperhidrosis are distinguished: primary; focal (sweating includes certain parts of the body - focal excessive sweating of hands and/or feet, armpits, face); generalized (affects the whole body), and secondary - sweating is a result of other diseases, such as chronic infections (tuberculosis, brucellosis - characterized by night sweats), endocrine diseases (diabetes, hyperthyroidism, hypoglycaemia), cancer (leukaemia, Hodgkin's disease, lymphoma, pheochromocytoma), neurological disorders (autonomic dysfunction in various diseases), syringomyelia, acromegaly, poisonings (acetylcholinesterase inhibitors, pesticides) [4, 51, 52].
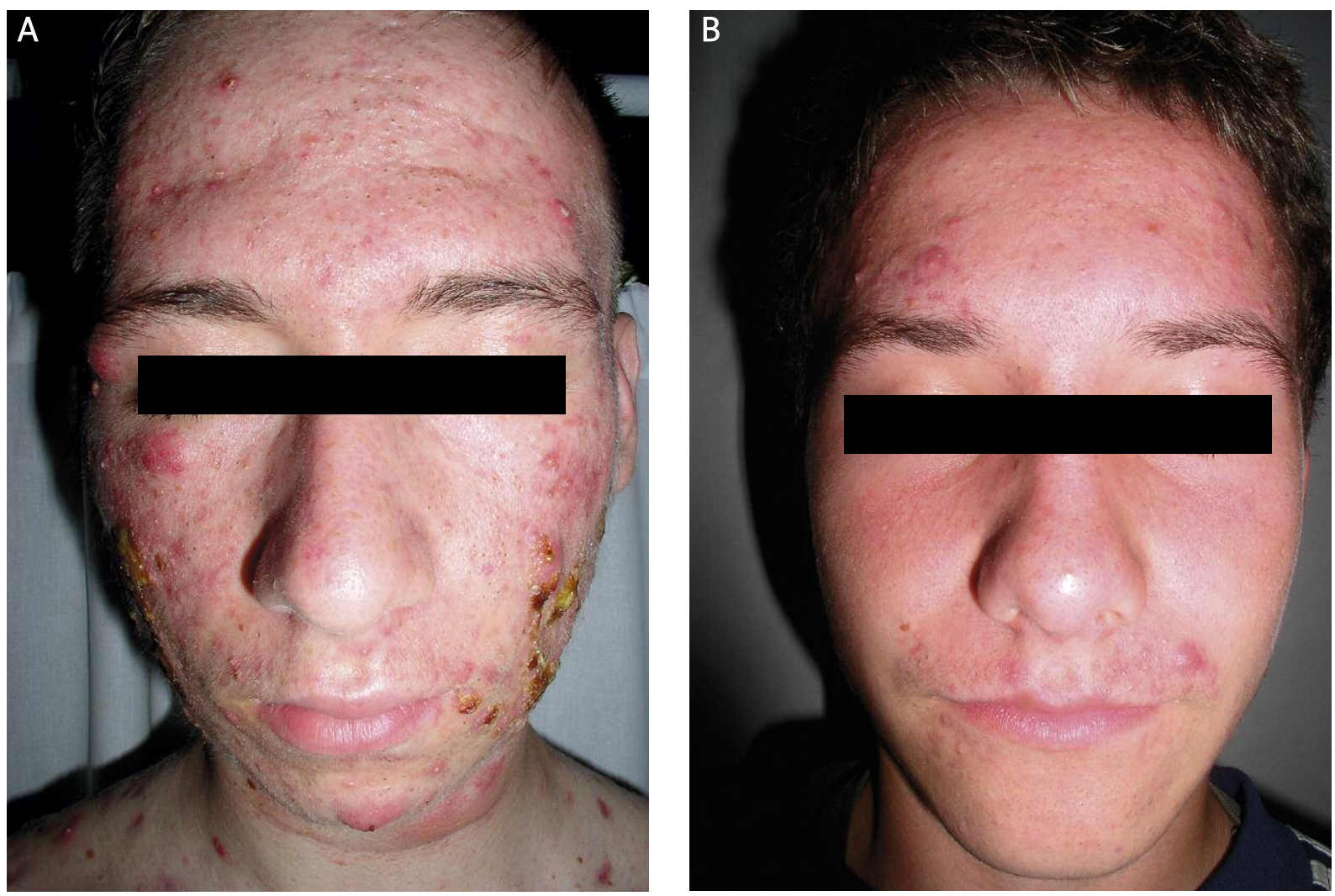

Fig. 2 A, B. Acne conglobata 
During puberty, excessive sweating can have an emotional basis, but it is also related with hormonal disturbances, characteristic of this period. Hyperhidrosis can also accompany improper diet consisting of warm and hot meals and drinks. Due to the fact that there are no physiological norms of the sweat production, diagnosis of hyperhidrosis is based on a patient's subjective opinion. In clinical studies, the resting sweat production over $20 \mathrm{mg} / \mathrm{min}$ and more than $50 \mathrm{mg} / \mathrm{min}$ in the armpits are believed to be abnormal $[4,53]$.

Treatment of excessive sweating is difficult and it frequently brings no expected results. Treatment includes antiperspirants (as the ready-to-use cosmetics or treatments containing aluminium chloride), cholinolytic drugs (Bellergot consisting of a mixture of ergot alkaloids, ergonovine and phenobarbital), clonidine, iontophoresis for sweating of feet and armpits, botulinum toxin, surgical methods (liposuction or curettage of sweat glands localised in armpits) and endoscopic thoracic sympathectomy (ETS) $[54,55]$.

\section{Hair diseases of the puberty}

Seborrhoeic dermatitis of the scalp is a chronic, relapsing, inflammatory dermatosis, which currently affects about $5 \%$ of the population $[56,57]$. It affects mostly young people, particularly men. An increased activity of the sebaceous glands, certain immunological phenomena, excessive colonization with Malassezia spp. and exogenous clinical factors play a key role in the pathogenesis of seborrhoeic dermatitis of the scalp [58]. An increased activity of the sebaceous glands in the aetiology of seborrheic dermatitis of the head is believed to be primarily related with disturbances of the sebaceous gland function and abnormalities in the composition of sebum [58]. Excessive sebum production results in exfoliation and irritation of the skin [59]. Disturbances of the sebum secretion include its increased production, increased content of cholesterol, triglycerides and paraffin fractions with a reduced content of free fatty acids, squalene and wax esters. Androgens are among the hormonal factors that may affect the function of the sebaceous glands. It is believed that localisation of skin changes in the course of seborrhoeic dermatitis and the low activity of the disease before the onset of puberty confirms the role of sebaceous glands in the pathogenesis of seborrhoeic dermatitis [59]. However, no clear link between sebum production and the development of skin lesions has been confirmed for seborrhoeic dermatitis. In adults, seborrhoeic dermatitis of the scalp does not need to be related with the increased scalp seborrhoea. An early symptom is the scalp seborrhoea but it does not always occur [59]. Then, oily scabs mount, inflammation occurs and the hair starts to thin significantly. The erythematous-scaly foci expand to the adjacent hairless areas, mostly on the forehead, behind the ears and neck. The patient's general condition is good. The severity of itch-

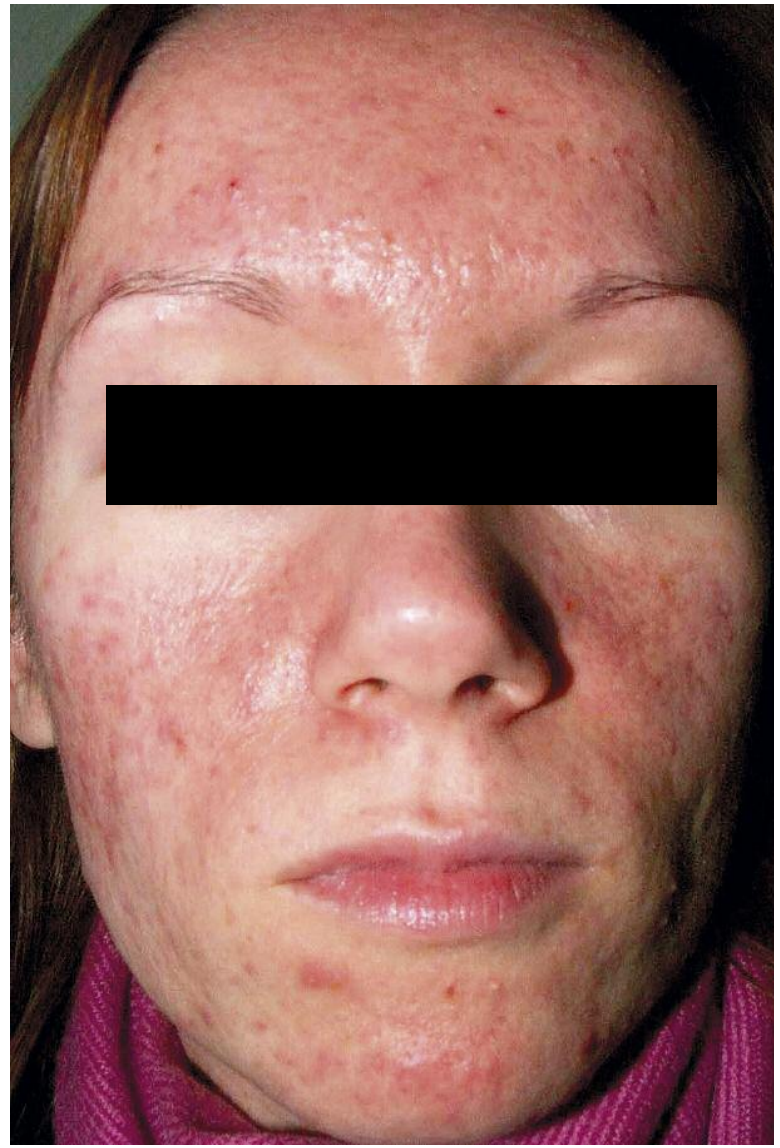

Fig. 3. Papulopustular acne

ing is different and the condition intensifies in autumn and winter periods [60].

Treatment of seborrheic dermatitis constitutes a difficult therapeutic problem. Co-operation with a patient is necessary to obtain satisfactory effects, the patient should comply with recommendations and should avoid factors exacerbating the disease such as stress or improper diet [60]. Shampoos, lotions and oils are used for treatment. These preparations are aimed at alleviation of clinical symptoms, decreasing inflammation and seborrhoea, but the best results are observed with the use of occlusions [61, 62]. The keratolytic, cytostatic and antifungal preparations are also used in the treatment. Formulations that reduce the yeast from the Malassezia genus are mostly imidazoles and ciclopiroxolamine, which have antibacterial, anti-inflammatory and anti-fungal action. Preparations containing selenium sulfide, zinc pyrithione, sulphur, salicylic acid and tar are also used in the treatment of seborrhoeic dermatitis of the scalp $[63,64]$. Furthermore, some researchers recommend the external use of the corticosteroid preparations in the form of liquids and aerosols, which reduce inflammation and itching. However, this treatment should be very prudent due to the possibility of side effects. Recently, there have been a lot of papers on the treatment of seb- 


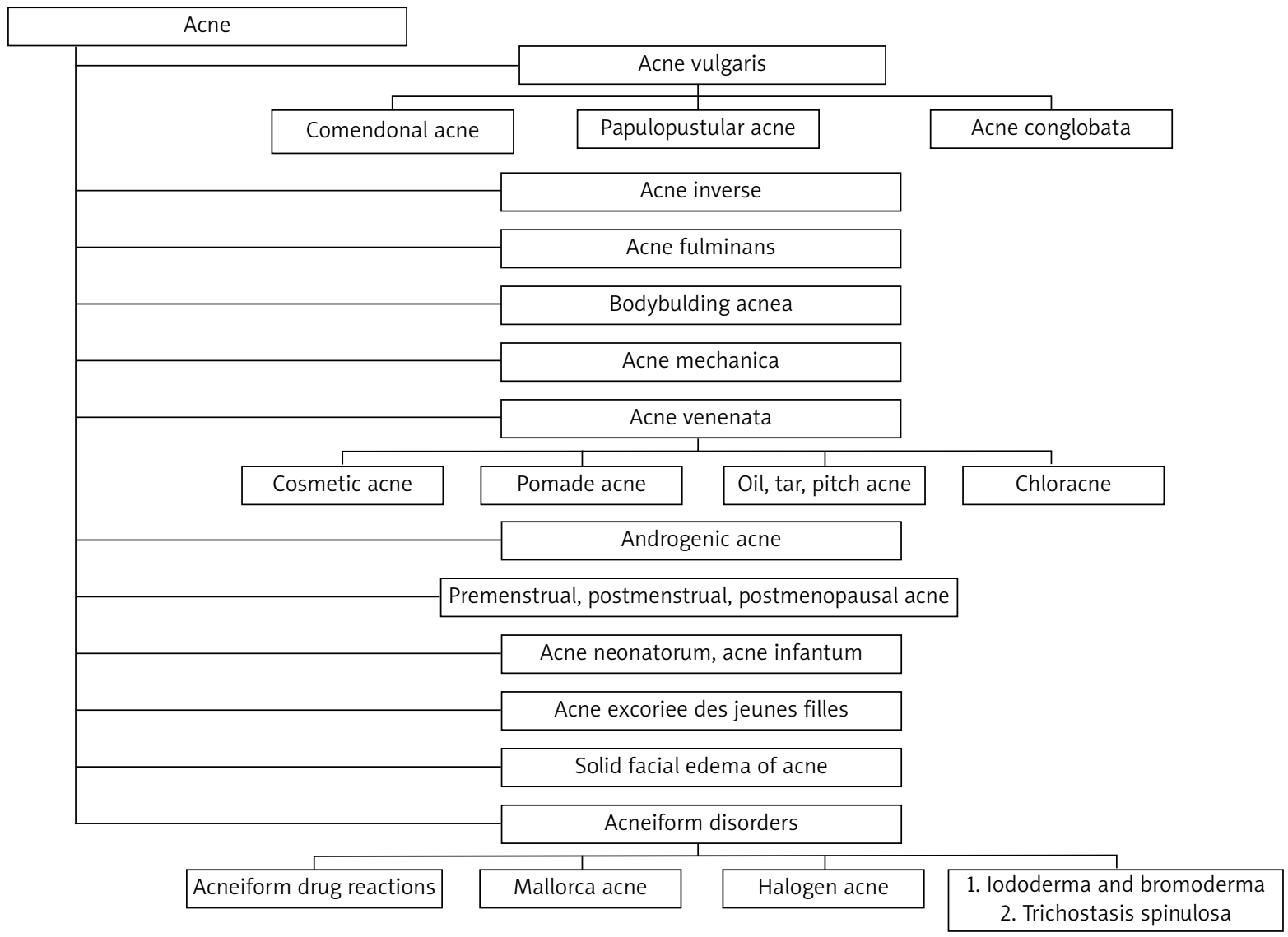

Fig 4. Various kinds of acne

Table 1. Treatment of acne

\begin{tabular}{|c|c|c|c|c|c|}
\hline & $\begin{array}{l}\text { Comedonal } \\
\text { acne }\end{array}$ & $\begin{array}{l}\text { Papulopustular } \\
\text { acne mild }\end{array}$ & $\begin{array}{l}\text { Papulopustular } \\
\text { acne medium }\end{array}$ & Nodular acne & Nodular/cystic acne \\
\hline $\begin{array}{l}\text { First-line } \\
\text { therapy }\end{array}$ & Local retinoid & $\begin{array}{l}\text { Local retinoid, } \\
\text { antibacterial drug }\end{array}$ & $\begin{array}{l}\text { Oral antibiotic + local } \\
\text { retinoid + benzyl peroxide }\end{array}$ & $\begin{array}{l}\text { Oral antibiotic + local } \\
\text { retinoid + benzyl peroxide }\end{array}$ & Oral isotretinoin \\
\hline $\begin{array}{l}\text { Alternative } \\
\text { therapy }\end{array}$ & $\begin{array}{l}\text { Local retinoid, } \\
\text { azelaic acid, } \\
\text { salicylic acid }\end{array}$ & $\begin{array}{l}\text { Local retinoid, } \\
\text { antibacterial drug } \\
+ \text { alt. local retinoid } \\
\text { or salicylic acid }\end{array}$ & $\begin{array}{l}\text { Alt. oral antibiotic }+ \text { alt. } \\
\text { local retinoid + benzyl } \\
\text { peroxide }\end{array}$ & $\begin{array}{l}\text { Oral isotretinoin or alt. } \\
\text { oral antibiotic + alt. local } \\
\text { retinoid + benzyl peroxide } \\
\quad+\text { azelaic acid }\end{array}$ & $\begin{array}{l}\text { High dose of oral } \\
\text { antibiotic }+ \text { local } \\
\text { retinoid }+ \\
\text { benzyl peroxide }\end{array}$ \\
\hline $\begin{array}{l}\text { Alternative } \\
\text { therapy for } \\
\text { women }\end{array}$ & $\begin{array}{l}\text { See first-line } \\
\text { therapy }\end{array}$ & $\begin{array}{l}\text { See first-line } \\
\text { therapy }\end{array}$ & $\begin{array}{l}\text { Oral antiandrogens + } \\
\text { local retinoid, azelaic acid, } \\
\text { local antibacterial drug }\end{array}$ & $\begin{array}{l}\text { Oral antiandrogens }+ \\
\text { local retinoid } \pm \\
\text { oral antibiotic } \pm \\
\text { alt. antibacterial }\end{array}$ & $\begin{array}{l}\text { High dose of } \\
\text { antiandrogens }+ \\
\text { local retinoid }+ \\
\text { local antibacterial } \\
\text { drug }\end{array}$ \\
\hline $\begin{array}{l}\text { Supportive } \\
\text { therapy }\end{array}$ & Local retinoid & Local retinoid & $\begin{array}{l}\text { Local retinoid }+ \text { benzyl } \\
\text { peroxide }\end{array}$ & $\begin{array}{l}\text { Local retinoid }+ \text { benzyl } \\
\text { peroxide }\end{array}$ & $\begin{array}{l}\text { Local retinoid + } \\
\text { benzyl peroxide }\end{array}$ \\
\hline
\end{tabular}

orrhoeic dermatitis of the scalp using calcineurin inhibitors $[65,66]$. Treatment also uses phototherapy, especially lamps emitting a narrow band UVB (comb). Some researchers, however, mention a possibility of temporary exacerbation of skin lesions or irritations [67]. Prevention of this disease is very important. Treatment requires a lot of patience on the part of both the patient and the doctor since the resulting improvement is often temporary. After the skin lesions disappear, patients should prophylactically use shampoos with ciclopiroxolamine or ketoconazole once a week for 
a few months and observe the proper hygiene and skin care [67]. However, dandruff of the scalp concerns $5-10 \%$ of the population with the greatest intensity at the age of 15-20 years [68-70]. It occurs more often in men than women. Changes become more severe in the winter. Dandruff is the peeling of the superficial cornified epidermal layers of the scalp and it occurs in the form of silver-gray scales. The aetiology of dandruff considers a possibility of infection with the yeast-like fungus Malassezia spp., hormonal disturbances, involvement of numerous exogenous factors and the failure of the epidermal cells renewal process [71-74].

Shampoos containing antifungal preparations bring about the greatest therapeutic effect [75]. Shampoos used in the treatment of dandruff should be regularly replaced with preparations of different groups because it prevents from the development of tachyphylaxis [75]. In the treatment of dandruff, antifungal, keratolytic or cytostatic preparations are used. Ciclopiroxolamine, which inhibits the growth of pathogenic fungi, Gram-positive and Gram-negative bacteria, synthesis of leukotrienes and prostaglandins is a comprehensive drug combining antibacterial, antifungal and anti-inflammatory action. For prophylaxis, it is recommended to use ciclopiroxolamine in the form of a shampoo or a ketoconazole shampoo once a week for at least 3 months.

Numerous physical and chemical factors, most commonly associated with improper hair care and beauty treatments, may cause certain changes in the structure of the hair shaft. Mechanical damage is the most common reason. Damage may result from excessive and improper combing and brushing, perming, cutting with blunt tools, straightening, using hair dryers, brushes or curlers with a too hot stream of air, intense and long sunlight, hair lightening and dyeing, bathing in salt water, and scratching or rubbing of the scalp due to a scalp disease. Other reasons are a result of unknown endogenous causes [76, 77].

The fair hair of young women are most commonly involved. In these disorders the hair become thin, breakable, matt, brittle and dry. Avoidance of injuries allows for re-growth of normal healthy hair, although many disorders are difficult to treat. A patient can try to use general vitamin supplements (especially of vitamin $\mathrm{H}$ ) and try to grease the scalp, which causes periodic improvements. The most important structural abnormalities include ringed, twisted, fleecy, moniliform, bamboo and knotty hair [78, 79].

One should remember about the physiological hair loss that can occur during puberty in approximately $20 \%$ of girls. This is slightly more common in boys in the form of a slight thinning of hair in the frontal and temporal angles, related with the action of male sex hormones. Occasionally, this can be the start of baldness of a male pattern in both sexes.

The last disease entity, which should be discussed in the trichology section that may occur in young people is androgenic alopecia (AGA). On average, one third of men aged 20-30 experiences a loss of hair of varying severity. For many of them, this is a serious psychological problem
- hair loss is considered to be a sign of aging and makes men perceive themselves as less attractive. If the hair is lush and well-cared for, it is associated with health, and it contributes positively to the social perception of a person. At the moment, when a perfect look counts, a hair loss can have a negative impact on the quality of life. Increased receding is observed in spring and autumn, but the haircut and shaving does not bring any improvement to the condition of hair [79]. Although hair loss appears in women older than 30 years, it is much rarer, so this issue will not be discussed here.

Genetic and hormonal factors are decisive in the pathogenesis of androgenic alopecia. Alopecia is inherited autosomally with a dominant gene of a variable penetration. Androgens are the second pathogenetic factors. Dihydrotestosterone (DTH) plays the main role. This is a tissue metabolite of testosterone. In the genetically predisposed hair follicles, the locally active enzyme, $5 \alpha$ reducer type 2 converts the testosterone into DHT, the latter directly involved in pathogenesis. DHT stimulates growth of the hair follicles localised in the facial and genital areas but it inhibits hair growth on the scalp [80, 81].

The "male pattern baldness", also called "classic baldness" starts from the hair loss beginning above both temples. Hair also thins at the crown of the head, followed by an " $M$ " shape on the parietal and temporal area leaving a rim of hair partially around the sides and rear of the head. Posterior and apical alopecia are observed in men and according to Hamilton are classified into I-VIII stages [82].

Minoxidil at a concentration of $2 \%$ and $5 \%$ is recommended for topical treatment of alopecia in men. It decreases the hair loss, stimulates growth and normalizes the condition of the hair roots. First effects can be observed already after 2 months, while certain signs of re-growth can be observed after a 4-month therapy and it is believed that the treatment should be started in the patients at the early stage of alopecia $[83,84]$.

Finasteride is recommended for general treatment of men with AGA. This compound blocks systemic conversion of testosterone to DHT - an androgen of stronger activity, while it does not inhibit ligation of testosterone and DTH with androgenic receptors and has no influence upon other steroid hormones. Finasteride decreases DHT levels in serum, the prostate gland and the skin. Therefore, it protects from the miniaturisation of the existing hair follicles and leads to the reversal of the balding process (increases the hair number, inhibits hair loss and has a positive influence upon the hair appearance). It is a safe and effective treatment for men who cannot accept the hair loss related with AGA. Practically, it has no side effects in men (it causes sexual dysfunction in about $2 \%$ of men) [85].

The use of finasteride and minoxidil is effective also in patients, who qualify for surgical treatment. Hair transplant gives good results in men. This method is very tedious and long-term, it requires enormous patience on the doctor's and the patient's part. Bald areas are covered with small 
tufts of skin grafts containing hair follicles taken out from the peripheral sites of the head where the hair is well preserved. The technique of mini- and micro-transplants was developed at the end of the 20th century. The use of this technique allows to obtain an effect that is the most consistent with the patient's expectations, but also with a further prognosis of baldness development. Contradictions to this procedure are compensation of psychological problems, exaggerated expectations of a patient, active skin diseases, a negative ratio of the donor area to the size of baldness and tendency for keloids development [85].

\section{References}

1. Jenerowicz D, Silny W, Dańczak-Pazdrowska A, et al. Environmental factors and allergic diseases. Ann Agric Environ Med 2012; 19: 475-81.

2. Żukiewicz-Sobczak W, Krasowska E, Zwoliński J, et al. Allergic diseases - current state of knowledge. Postep Derm Alergol 2012; 29: 451-5.

3. Koo JY, Smith LL. Psychologic aspects of acne. Pediatr Dermatol 1991; 8: 185-8.

4. Braun-Falco O, Burgdorf WHC, Plewig G, et al. Dermatology. Czelej, Lublin 2010.

5. Ramos-e-Silva M, Carneiro SC. Acne vulgaris: review and guidelines. Dermatol Nurs 2009; 2: 63-8.

6. James KA, Burkhart CN, Morrell DS. Emerging drugs for acne. Expert Opin Emerg Drugs 2009; 14: 649-59.

7. Shamban AT, Narurkar VA. Multimodal treatment of acne, acne scars and pigmentation. Dermatol Clin 2009; 27: 459-71.

8. Plewig G. How acne vulgaris develops. Hautarzt 2010; 61: 99-100, 102-4, 106

9. Webster G, Rawlings A. Acne. Diagnostic and treatment. Czelej, Lublin 2009.

10. Thiboutot D, Gollnick $H$. The modern view of acne treatment: World Group of Experts. Dermatol Cosmetol 2009; 9: 4-52.

11. Thiboutot D. Pathogenesis and treatment of acne. J Eur Acad Dermatol Venerol 2001; 15: 91.

12. Uhlenhake E, Yentzer BA, Feldman SR. Acne vulgaris and depression: a retrospective examination. J Cosmet Dermatol 2010; 9: 59-63.

13. Gollnick H, Schramm M. Topical drug treatment in acne. Dermatology 1998; 196: 119-25.

14. Morel P, Vienne MP, Belyot C, et al. Antibiotic sensitivity of Propionibacterium acnes isolates studied in a skin clinic in Singapore. Arch Dermatol 1999; 24: 723.

15. Wolska $\mathrm{H}$. The role of combined therapy in acne treatment. Derm Klin Zabieg 2001; 3: 129.

16. Eady EA. Bacterial resistance in acne. Dermatology 1998; 196: 59-66.

17. Mourelatos K, Eady EA, Cunliffe WJ, et al. Temporal changes in sebum excertion and priopionibacterial colonization in preadolescent children with and without acne. Br J Dermatol 2007; 156: 22-31.

18. Grange PA, Chereau C, Raingeaud J, et al. Production of superoxide anions by keratinocytes initiates P. acnes-induced inflammation of the skin. Plos Pathog 2009; 5: e1000527.

19. Kang BS, Seo JG, Lee GS, et al. Antimicrobial activity of enterocins from Enterococcus faecalis SL-5 against Propionibacterium acnes, the causative agent in acne vulgaris, and its therapeutic effect. J Microbiol 2009; 47: 101-9.
20. Lyte P, Sur R, Nigam A, et al. Heat-killed Propionibacterium acnes is capable of inducting inflammatory responses in skin. Exp Dermatol 2009; 18: 1070-2.

21. Vega B, Jomard A, Michel S. Regulation of human monocyte Toll-like receptor 2 (TLR2) expression by adapalene. J Eur Acad Dermatol Venerol 2002; 16: 123.

22. Elsaie ML, Choudhary S, Kammer JN. New insights into adolescent acne. G Ital Dermatol Venereol 2009; 144: 645-62.

23. Bergler-Czop B, Brzezińska-Wcisło $L$. The results of acne conglobata treatment with oral isotretinoin - 10 years observation in patients of Department of Dermatology Silesian Medical University. Dermatol Klin 2005; 2: 73-7.

24. Miller LS. Toll-like receptors in skin. Adv Dermatol 2008; 24: 71-87.

25. Holland KT, Holland DB, Cunliffe WJ, et al. Detection of Propionibacterium acnes polypeptides which have stimulated an immune response in acne patients but not in normal individuals. Exp Derm 1993; 2: 12-6.

26. Melnik BC. FoxO1 - the key for the pathogenesis and therapy of acne? I Dtsch Dermatol Ges 2010; 8: 105-14.

27. Sarici G, Cinar S, Armutcu F, et al. Oxidative stress in acne vulgaris. J Eur Acad Dermatol Venereol 2010; 24: 763-7.

28. Zoubolis CC, Seltmann H, Hiroi N, et al. Corticotrophin-relasing hormone: an autocrine hormone that promotes lipogenesis in human sebocytes. Proc Natl Acad Sci 2002; 99 : 7148-53.

29. Bergler-Czop B, Brzezińska Wcisło L. Hormonal factors in acne vulgaris. Pol Merkuriusz Lek 2004; 16: 490-2.

30. Kurokawa I, Danby FW, Ju Q, et al. New developments in our understanding of acne pathogenesis and treatment. Exp Dermatol 2009; 18: 821-32.

31. Lolis MS, Bowe WP, Shalita AR. Acne and systemic disease. Med Clin North Am 2009; 93: 1161-81.

32. Bellew S, Thiboutot D, Del Rosso JQ. Pathogenesis of acne vulgaris. What's new. What's interesting and what may be clinically relevant. J Drugs Dermatol 2011; 1: 582-5.

33. Wolska H, Langner A, Stąpór W. Diagnostics and optimalization of acne treatment (acne vulgaris). Medipress 1997; 4: 2-12.

34. Zouboulis CC, Makrantonaki E. Clinical aspects and molecular diagnostics of skin aging. Clin Dermatol 2011; 29: 3-14.

35. Brzezińska-Wcisło L, Bergler-Czop B, Wcisło-Dziadecka D. What's new in acne etiology? Dermatol Klin 2006; 4: 275-9.

36. Katsambas AD, Dessinioti C. Hormonal therapy for acne: why not as first line therapy? Facts and controversies. Clin Dermatol 2010; 28: 17-23.

37. Ahsan MK, Urano Y, Kato S, et al. Immunohistochemical localisation of thyroid hormone nuclear receptors in human hair folicles and in vitro effect of L-triiodothyronine on cultured cells of hair follicles and skin. Lab Med Invest 1998; 44: 179-84.

38. Bohm M, Schiller M, Brzoska T, et al. Expression of melanocortin-1 receptor in human sebocytes in vitro and in situ. J Invest Dermatol 2002; 118: 533-9.

39. Thiboutot D, Gilliland BS. Androgen methabolism in sebaceous glands from subjects with and without acne. Arch Dermatol 1999; 135: 1041-5.

40. Zaidi Z. Dispelling the myths and misconceptions of acne. J Pak Med Assoc 2009; 5: 264-5.

41. Yang Z, Yu H, Cheng B, et al. Relationship between the CAG repeat polymorphism in the androgen receptor gene and acne in the Han ethnic group. Dermatology 2009; 4: 302-6.

42. Bergler-Czop B, Brzezińska-Wcisło L. Methods of acne treatment in Department of Dermatology Silesian Medical University in years 1991-2000. Wiad Lek 2005; 41: 56-160. 
43. Marcason W. Milk consumption and acne: is there a link? J Am Diet Assoc 2010; 110: 152.

44. Allen M, Gratchtchouk M, Sheng $\mathrm{H}$. Hedgehog signaling regulates sebaceous gland development. Am J Path 2003; 163 2173-8.

45. Hsu P, Litman GI, Brodell RT. Overview of the treatment of acne vulgaris with topical retinoids. Postgrad Med 2011; 123 153-61.

46. Bergler-Czop B. Early and late results of treatment various kind of acne in Department of Dermatology Silesian Medical University in years 1991-2000. Śląska Akademia Medyczna, Katowice 2003.

47. Laubscher $T$, Regier $L$, Jin $M$, et al. Taking the stress out of acne managment. Can Fam Physician 2009; 55: 266-9.

48. Aldana OL, Holland DB, Cunliffe WJ. Variation in pilosebaceous duct kerationocyte proliferation in acne patients. Dermatology 1998; 196: 98-9.

49. Worobec SM, Wong FA, Tolman EL. Percutaneous absorption of $3 \mathrm{H}$-tretinoin in normal volunteers. I Invest Dermatol 1991; 96: 574A.

50. Kravarusic D, Freud E. Thoracoscopic sympathectomy gan glia ablation in the management of palmer hyperhidrosis: a decade experience in a single institution. Afr J Paediatr Surg 2012; 9: 143-7.

51. Dressler D. Botulinum toxin therapy: its use for neurological disorders of the autonomic nervous system. J Neurol 2012; 8: 193-5.

52. Hölzle E, Bechara FG. Pathophysiology, clinical features and diagnosis of hyperhidrosis. Hautarzt 2012; 63: 448-51.

53. Schneier FR, Heimberg RG, Liebowitz MR, et al. Social anxiety and functioetnal impairment in patients seeking surgical evaluation for hyperhidrosis. Compr Psychiatry 2012; 7 : 23-7.

54. Streker M, Kerscher M. Antiperspirants for the therapy of focal hyperhidrosis. Hautarzt 2012; 63: 452-5.

55. Hosp C, Naumann MK, Hamm H. Botulinum toxin in focal hyperhidrosis: an update. Hautarzt 2012; 63: 469-76.

56. Del Rosso JQ. Adult seborrheic dermatitis: a status report on practical topical management. J Clin Aesther Dermatol 2011; 4: 32-8.

57. Brzezińska-Wcisło L, Wcisło-Dziadecka D, Bergler-Czop B. News in pathogenesis and therapy of seborrhoic dermatitis. Dermatol Prakt 2011; 4: 7-13.

58. Lis A, Wcisło-Dziadecka M, Kamińska G. Physiology and pathology of growth and loss of human scalp hair. Postep Derm Alergol 2003; 20: 260-6.

59. Braun-Falco O. Plewig G, Wolff HH, Burgdorf WHC. Inflammation of the skin. In: Dermatology. Braun-Falco O, Plewig G, Wolff HH, Burgdorf WHC (eds). Czelej, Lublin 2002; 462-6.

60. Baran E, Szepietowski J, Maleszka R, et al. Seborrhoic dermatitis - therapuetic scheme. PDS recommendation. Dermatol Klin 2006; 4: 229-34.

61. Szepietowski J, Reich A. Treatment of skin and sexual transmitted disease. PZWL, Warsaw 2002.

62. Brzezińska-Wcisło L. What is new in the etiopathogenesis and treatment of dermatitis seborrhoica. Postep Derm Alergol 2005; 22: 10-3.

63. Wcisło-Dziadecka D, Lis-Święty A, Trzmiel D. Dandruff and seborrhoeic dermatitis of the scalp - pathogenesis, clinical picture and therapeutic aspects. Postep Derm Alergol 2007; 24: 59-64.

64. Czyż P, Ryglewska-Cho A, Miękoś-Zydek B, et al. News in pathogenesis and treatment of seborrhoic dermatitis. Nowa Klin 2003; 10: 1104-6.
65. Johnson B, Nunley J. Treatment of seborrheic dermatitis. Am Fam Physician 2000; 61: 2703-10.

66. Shin $\mathrm{H}$, Kwon OS, Won $\mathrm{CH}$, et al. Clinical efficacies of topical agents for the treatment of seborrheic dermatitis of the scalp: a comparative study. J Dermatol 2009; 36: 131-7.

67. Kerr K, Schwartz JR, Filloon T, et al. Scalp stratum corneum histamine levels: novel sampling method reveals association with itch resolution in dandruff/seborrhoeic dermatitis treatment. Acta Derm Venereol 2011; 21: 11-4.

68. Biber T. Other inflammation of the skin. In: Dermatology. Gliński W, Czarnecka-Operacz M, Krakowska D, et al. (eds). Czelej, Lublin 2010; 442-51.

69. Gupta AK, Madzia SE, Batra R. Etiology and management of seborrheic dermatitis. Dermatology 2004; 208: 89-93.

70. Nowicki R. $1.5 \%$ cyclopiroxolamin shampoo in dandruff treatment. Przew Lek 2004; 9: 66-71.

71. Adamski Z. Dandruff as a dermatology problem. Mikol Lek 2002; 1: 21-4.

72. Zawirska A. Yeast of the genus Malassezia. New data. Postep Derm Alergol 2004; 21: 97-103.

73. Salomon J, Szepietowski J. Seborrhoic dermatitis - pathogenesis, clinics and therapy. Dermatol Klin 2006, 8: 127-31.

74. Gupta AK, Nicol KA. Seborrheic dermatotis of the scalp: etiology and treatment. J Drugs Dermatol 2004; 3: 155-8.

75. Nowicki R. Modern treatment of dandruff. Pol Merkuriusz Lek 2006; 20: 121-4.

76. Kostanecki W. Hair disease. PZWL, Warsaw 1979.

77. Lis-Święty A, Wcisło-Dziadecka D, Rogala-Poborska I, Trzmiel D. Congenital and acquired changes of hair structure. Postep Derm Alergol 2007; 24: 282-9.

78. Nowicka D, Reich A, Szepietowski J. Psychologic aspects of male androgenic alopecia. Dermatol Klin 2005; 7: 35-6.

79. Brzezińska-Wcisło L, Wcisło-Dziadecka D, Lis-Święty A, et al. What's new in pathogenesis and treatment of androgenic male alopecia. Dermatol Klin 2007; 9: 179-81.

80. Sawaya ME, Shapiro J. Androgenetic alopecia. Dermatol Clin 2000; 1: 47-61.

81. Hamilton JS. Patterned loss of hair in man, types and incidence. Ann N Y Acad Sci 1951; 53: 708-12.

82. Placek W, Kallas D, Czaplewski W, et al. Male androgenic alopecia. Świat Med Farm 2004; 5: 540-7.

83. Jabłońska S. Majewski S. Male androgenic alopecia. In: Skin disease and sexual transmitted disease. Jabłońska S, Majewski S (eds). PZWL, Warsaw 2005; 450-1.

84. Ryn HK, Kim KM, Yoo EA, et al. Evaluation of androgens in the scalp hair and plasma of patients with male - patttern baldness before and after finasteride administration. $\mathrm{Br}$ J Dermatol 2006; 154: 230-4.

85. Leavitt M, Perez-Meza D, Rao-Naveen A et al. Effects of finasteride (1 mg) on hair transplant. Dermatol Surg 2005; 31: 1268-76. 